\title{
Sistem Penjejak Ikan untuk Pemantauan Kualitas Lingkungan Perairan dan Prediksi Lokasi Penangkapan Ikan menuju Pengelolaan Perikanan Berkelanjutan
}

\section{Intelligent Fish Tracker System for Monitoring the Quality of Waters Environment and Fishing Ground Prediction toward Sustainable Fishery Management}

\author{
MUHAMAD SADLY DAN AWALUDDIN \\ Pusat Teknologi Pengembangan Sumberdaya Wilayah, Badan Pengkajian dan Penerapan Teknologi \\ Gedung II BPPT, Lantai 15, JI. M. H. Thamrin 8, Jakarta 10340 \\ muhamad.sadly@bppt.go.id
}

\begin{abstract}
This research proposed a new approach in the development of fishing ground prediction model and the quality of environmental monitoring in the sea, especially for economic pelagic fish. Knowledge-Based Expert System that is integrated with Remote Sensing and Geographic Information System was decided as a new approach in order to improve the existing conventional method. The model developed was called "Intelligent Fish Tracker". The main problems of a conventional method are the estimation of fishing ground using manual system and the result obtained that is not optimal and impractical in its implementation. We used a series remote sensing satellite data of sea surface temperature (SST), sea surface chlorophyll-a (SSC) and turbidity derived from Aqua MODIS in period of 2007-2014 years as input data. Spatial map of the predicted fishing ground spots was then developed and generated by the ERDAS Macro Language of ERDAS Imagine. To verify and validate the result, a series of in-situ fishing ground spots data of the study area were collected for the similar periods, and they were then analyzed by using a simple statistical method. The result showed that the predicted fishing ground (FG) densities and the quality of sea environment in Banggai island waters generated by the proposed model was well correspond to in-situ data with high accuracy level of more than $93 \%$. The result demonstrated that the proposed model can be applied to predict, localize and determine fishing ground densities, in which their accuracy level are higher than conventional method. The proposed model was implemented using online system.
\end{abstract}

Keywords : expert system, fishing ground, remote sensing, intelligent fish tracker, geographic information system

\begin{abstract}
ABSTRAK
Dalam riset ini diusulkan suatu pendekatan baru di dalam membangun model prediksi lokasi penangkapan ikan dan pemantauan kualitas lingkungan perairan, khususnya ikan pelagis ekonomis. Knowledge-based expert system diintegrasikan dengan penginderaan jauh dan sistem informasi geografis dipilih sebagai pendekatan baru untuk menyempurnakan metode konvensional yang saat ini digunakan. Model yang dikembangkan disebut "Sistem Penjejak Ikan nan Cerdas". Kelemahan utama metode konvensional, penentuan lokasi penangkapan ikan masih dilakukan secara manual, akibatnya hasil yang diperoleh tidak optimal dan tidak praktis di dalam implementasinya. Data seri satelit penginderaan jauh (suhu permukaan laut, klorofil dan turbiditi) yang diperoleh dari satelit Aqua MODIS periode tahun 2007-2014 digunakan sebagai data input. Peta spasial sistem prediksi lokasi penangkapan ikan dibangun menggunakan ERDAS Imagine Macro Language. Untuk verifikasi dan validasi hasil, dilakukan pengambilan data in-situ fishing ground pada lokasi riset dalam periode waktu yang sama, dan telah di analisa dengan metode statistik untuk mendapatkan tingkat akurasinya. Hasil menunjukkan bahwa densitas fishing ground yang telah di prediksi dan kualitas lingkungan perairan di perairan Banggai Kepulauan dikorelasikan dengan data hasil survei lapangan (in-situ data) diperoleh tingkat akurasi lebih dari 93\%. Dari demonstrasi hasil, model yang diusulkan dapat diaplikasikan untuk memprediksi, melokalisasi dan menentukan densitas fishing ground dengan tingkat akurasi lebih tinggi dibanding metode konvensional. Sistem prediksi ini telah diimplementasikan pada sistem online.
\end{abstract}

Kata kunci : sistem pakar, lokasi penangkapan ikan, penginderaan jauh, sistem penjejak ikan nan cerdas, sistem informasi geografi 


\section{PENDAHULUAN}

Visi Presiden RI ke-7 menjadikan Indonesia sebagai Poros Maritim Dunia. Agenda pembangunan untuk mewujudkan Poros Maritim Dunia ini memiliki lima pilar utama. Salah satu pilar (Pilar ke 2) menyebutkan "menjaga dan mengelola sumberdaya laut”, dengan fokus membangun kedaulatan pangan laut, melalui pengembangan industri perikanan, dengan menempatkan nelayan sebagai pilar utama. Pengelolaan penangkapan ikan di laut yang baik dan seimbang memerlukan informasi potensi sumberdaya ikan laut yang baik dan akurat. Sejarah mencatat, negara negara yang sukses adalah mereka yang unggul dalam penguasaan samudera dan pengembangan geostrategi maritimnya. Indonesia dikenal sebagai benua maritim, dimana Indonesia memiliki lebih dari 17.500 pulau yang dikelilingi lautan. Menurut catatan Badan Informasi Geospasial (BIG), luas laut keseluruhan NKRI adalah 6.315.222 km2 dengan garis pantai terpanjang kedua di dunia seteah Kanada, dengan garis pantai sepanjang $99.093 \mathrm{~km}$, tak terbantahkan itu merupakan berkah bagi Indonesia. Namun, sejauh ini masih begitu banyak SDA Indonesia yang belum terjamah dan terinventarisasi dengan lengkap, khususnya sumberdaya laut (perikanan). Untuk mewujudkan visi tersebut diatas, maka tujuan utama dalam riset ini diusulkan suatu pendekatan baru di dalam membangun model sistem penentuan lokasi penangkapan ikan di laut (fishing ground/FG) dan sistem pemantauan kualitas lingkungan perairan dalam upaya peningkatan efektifitas perikanan tangkap ikan pelagis ekonomis.

Knowledge-based experts system ${ }^{(1)}$ yang diintegrasikan dengan teknologi penginderaan jauh (remote sensing) dan sistem informasi geografis (SIG) dipilih sebagai pendekatan baru di dalam upaya memperbaiki metode konvensional yang saat ini masih digunakan. Kelemahan utama dari metode konvensional adalah pemantauan kualitas lingkungan perairan dan penentuan lokasi penangkapan ikan (FG) masih dilakukan secara manual, akibatnya hasil yang diperoleh juga tidak optimal dan tidak praktis di dalam implementasinya. Model yang dikembangkan disini dinamakan Sistem Penjejak Ikan Nan Cerdas (Intellgent Fish Tracker). Knowledge based expert system (KBES) adalah cabang dari bidang kecerdasan buatan (Artificial Intelligencel/Al), merupakan sebuah pemrograman komputer yang memiliki kemampuan dalam proses berfikir seperti pakar dan dapat membuat keputusan dan rekomendasi, berdasarkan masukan dari user $(2,3)$. Observasi jarak jauh pada permukaan laut dapat menyediakan bagian penting dari informasi yang dibutuhkan untuk mengkaji dan menyempurnakan lokasi potensial penangkapan ikan. Parameter parameter lingkungan perairan kebanyakan diukur dari pesawat (airborne) dan menggunakan sensor satelit (spaceborne sensor ${ }^{(4)}$. Keunikan dari model yang diusulkan ini ditunjukkan dengan ciri-ciri sebagai sistem pendukung keputusan secara cerdas (intelligenct decision support system), fungsi obyektif meminimumkan biaya (cost minimizing objective function), serta mempunyai konsep maju, menguntungkan, sejahtera dan lestari/ berkelanjutan; dapat membantu pengguna (Kementerian/Lembaga, Pemda, PerguruanTinggi, Industri Perikanan dan institusi terkait lainnya) didalam menyusun perencanaan strategis dibidang kelautan \& perikanan. Lebih lanjut, sistem yang dibangun ini, mampu menjawab beberapa pertanyaan penting, misalnya mengenai: (i) posisi (koordinat) fishing ground/FG yang terdeteksi, (ii) jenis armada / kapal (tonase) alat tangkap dan prasarana penunjang apa yang layak digunakan, (iii) jarak dan lama waktu tempuh dan arah (haluan) dari pos pendaratan ikan ke titik FG, (iv) jenis ikan yang kemungkinan menjadi target tangkapan, (iv) besar modal, biaya operasional yang dikeluarkan, biaya produksi tangkapan dan estimasi keuntungan yang dihasilkan, (v) arah kemungkinan titik $F G$ akan bergerak sehingga bisa diprediksi target FG berikutnya, dan (vi) kondisi dinamika laut yang mempengaruhi $\mathrm{FG}$ yang ditemukan.

Proses yang dilakukan dalam riset ini adalah: Pertama, difokuskan pada pembangunan basis data spasial kelautan dan perikanan, pengumpulan data penginderaan jauh dan data lapangan, data kualitas lingkungan perairan. Kedua, pengembangan model prediksi, pengujian dan validasi, serta pembangunan sistem pemantauan kualitas lingkungan perairan dan sistem informasi fishing ground berbasis website spasial (online system). Untuk validasi hasil pengembangan model disini digunakan data seri satelit penginderaan jauh (suhu permukaan laut/SST, sea surface chlorophyll-a (SSC) dan kekeruhan/turbidity) diperoleh dari satelit Aqua MODIS U.S.A dalam periode tahun 2007 sampai 2014, serta data survei lapangan dilokasi yang sama dengan lokasi penelitian (in-situ data). Model prediksi dikembangkan dengan menggunakan ERDAS Imagine Macro Language $(\mathrm{EML})^{(5)}$.

Sistem ini juga dirancang berbasis online, agar mampu menyediaan informasi yang cepat (mudah di akses), akurat tentang lokasi penangkapan ikan dan kondisi kualitas lingkungan perairan. Diharapkan sistem ini juga dapat membantu meningkatkan pendapatan dan kesejahteraan masyarakat nelayan yang 
merupakan ujung tombak penangkapan ikan di laut.

\section{BAHAN DAN METODE}

\subsection{Lokasi Studi dan Akuisisi Data}

Daerah penelitian terletak di daerah perairan pesisir Banggai Kepulauan, Sulawesi Tengah (Gambar 1, kotak berwarna merah). Sebagai data input, digunakan Suhu Permukaan Laut (SST), Klorofil-a (SSC) dan data Kekeruhan berasal dari data satelit MODIS NASA U.S.A.. Sedangkan untuk memverifikasi dan validasi hasil pemantauan kualitas lingkungan perairan dan sistem prediksi lokasi penangapan ikan (fishing ground), dengan mengumpulkan data insitu dari titik penangkapan ikan di lokasi yang sama dalam kegiatan survei lapangan, dan analisis statistik sederhana digunakan untuk mendapatkan nilai akurasinya.

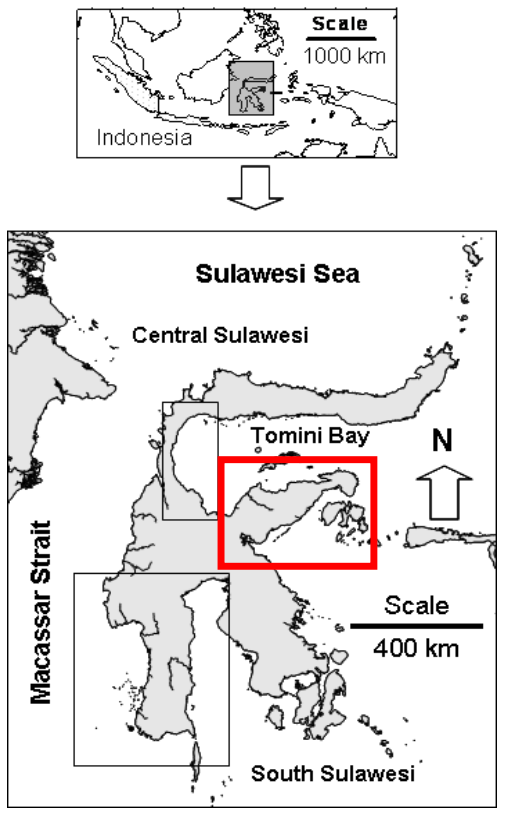

Gambar 1. Lokasi Studi (kotak merah)

Data seri satelit penginderaan jauh (suhu permukaan laut/SST, sea surface chlorophyll-a (SSC) dan turbidity) diperoleh dari satelit Aqua MODIS milik U.S.A dalam periode tahun 2007 sampai 2014 digunakan sebagai data input untuk memahami variabilitas waktu dan musim pada lingkungan perairan dan mengidentifikasi fenomena oseanografi.

\subsection{Metode}

Pada Gambar 2, diperlihatkan integrasi antara sistem pakar (expert system), sistem informasi geografis (GIS) dan penginderaan jauh (remote sensing/RS), yang merupakan konsep dasar yang digunakan dalam pembangunan model. Sistem integrasi disini merupakan metode baru (new method) yang digunakan dalam memetakan lokasi fishing ground berdasarkan hasil pemantauan kualitas lingkungan perairan di lokasi studi. Model prediksi yang diusulkan disini, dirancang untuk menjawab 3 (tiga) pertanyaan yang biasa dijumpai di dalam imlementasinya. Komponen GIS \& RS difasilitasi untuk menjawab pertanyaan pertanyaan "What" dan "Where", yaitu RS \& GIS database dan spatial analysis. Komponen expert system disusun dengan 2 (dua) modul utama, yaitu : Knowledge-Base dan inference engine yang difasilitasi untuk menjawab pertanyaan "Why". Basis pengetahuan (knowledge base) dari sebuah expert system dibangun berdasarkan hasil dari pengambilan pengetahuan (knowledge acquisition) di dalam bentuk "production rules", yang disusun dari sekumpulan aturan (heuristic rules) yang karakteristik nya dikenal dengan "IF-THEN Rule" ${ }^{\prime(6,7)}$. Inference engine adalah sebuah alat pemroses pengetahuan (knowledge processing tool) pada komponen expert system. Tugas utamanya adalah menggabungkan fakta fakta (facts) dengan aturan-aturan (rules) untuk mengembangkan atau untuk menyimpulkan atau untuk menggambarkan kesimpulan tentang faktafakta baru ${ }^{(8,9,10)}$.

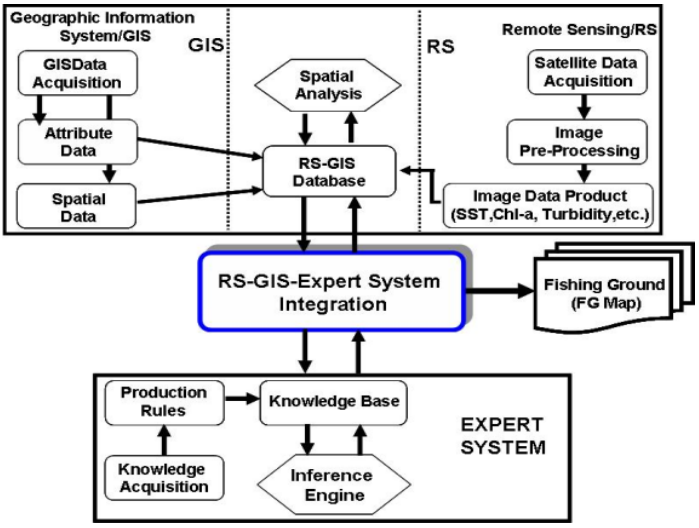

Gambar 2. Sistem integrasi Expert System, Remote Sensing, GIS yang digunakan dalam membangun model $^{(11)}$

Elemen terpenting dari model yang diusulkan disini adalah modul integrasi yang menghubungkan (link) komponen remote sensing, GIS (spatial analysis) dan mesin pengambil keputusan (inference engine), melalui basis data GIS dan basis pengetahuan (knowledge base).

\subsubsection{Rancang Bangun Sistem Pemantauan Kualitas Lingkungan Perairan dan Model Prediksi FG}

Proses penentuan lokasi penangkapan ikan (fishing ground) selanjutnya melalui para ahli/pakar (experts) disusun basis pengetahuan 
(knowledge base) tentang hubungan antara parameter-parameter yg mempengaruhi penentuan FG. Dalam penelitian ini, digunakan 3 (tiga) parameter oseanografi (SST, klorofil-a, kekeruhan/ turbiditi) sebagai data masukan (input data $)^{(12,13)}$. Parameter ini kemudian diproses untuk mengobservasi/ memantau kualitas lingkungan dan mengidentifikasi fenomena oseanografi di daerah lokasi penelitian yang diduga memiliki korelasi kuat dengan lokasi potensial penangkapan ikan (FG). Dalam penerapan model expert system menggunakan data harian dan data bulanan dari SST, Chl-a, dan kekeruhan (turbidity) sebagai variabel input untuk menghasilkan informasi harian/bulanan pembentukan densitas daerah potensial penangkapan ikan (14),(15). Proses perumusan hubungan antar parameter (ontologi) dalam rangka menghasilkan lokasi potensial penangkapan ikan ditunjukkan pada Gambar 3.

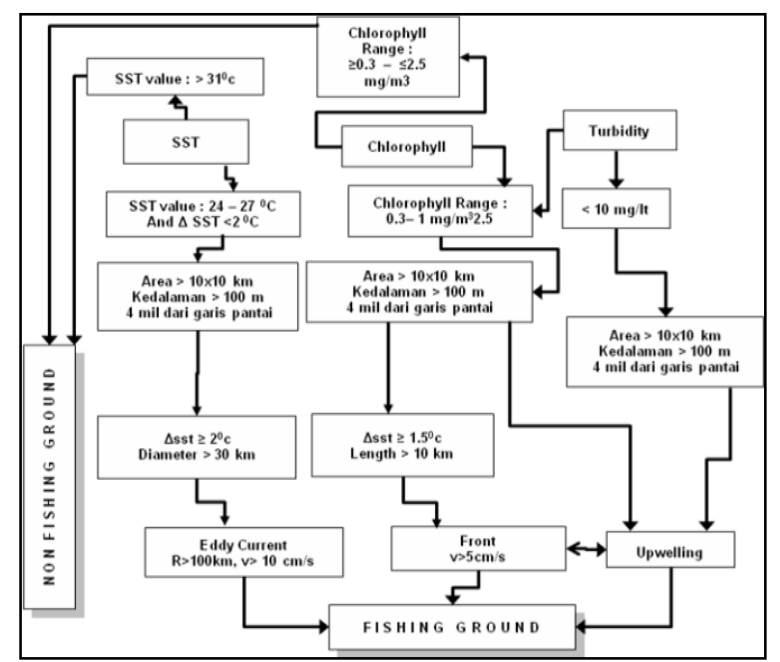

Gambar 3. Hubungan antar Parameter Oseanografi (Ontologi) dalam penentuan $\mathrm{FG}^{(11)}$

Hasil dari rumusan ontologi ini, selanjutnya diturunkan menjadi aturan-aturan (rules) yang digunakan didalam membangun model prediksi lokasi penangkapan ikan. Dari Gambar 3, diperlihatkan alur sistem, dimana hubungan antar parameter (Chl, SST, Turbidity), serta arus laut (Sea Surface Heigh) untuk memprediksi pergerakan ikan dan FG.

\subsubsection{Konsep Model Prediksi Untuk Penentuan Lokasi Fishing Ground}

Konsep pemodelan yang digunakan dalam pembangunan intelligent fish tracker ini dengan pendekatan Knowledge based expert system yang diintegrasi dengan GIS dan data penginderaan jauh didasarkan pada pendekatan model yang bersiklus (seperti diilustrasikan pada Gambar 4).
Model ini terdiri dari tiga (3) tahap, yaitu: (i). Tahap Pengamatan (observation): untuk menentukan karakteristik perilaku ikan, kondisi fisik laut dan menggunakan metode pengenalan pola daerah penangkapan ikan dan yang bukan daerah penangkapan ikan; (ii). Analisis dan interpretasi data (SST, Chl-a, dan turbidity; (iii). Model prediksi dan tahap pengujian/verifikasi : pengujian dan validasi menggunakan data in-situ untuk prediksi daerah penangkapan ikan (fishing ground).

Dari konsep model ini, kita akan memahami bahwa kinerja model akan tergantung pada data umpan balik (feedback) dari pengamatan lapangan (in-situ) dan basis pengetahuan yang dibangun oleh sistem pakar.

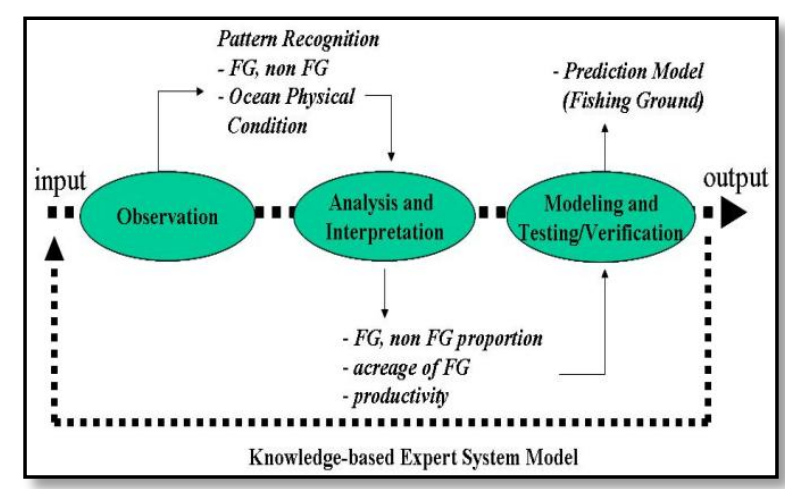

Gambar 4. Konsep Model Prediksi FG ${ }^{(11)}$

\subsubsection{Verifikasi Dan Validasi Model}

Untuk memverifikasi dan validasi hasil dari model yang dibangun untuk penentuan FG, dilakukan pengambilan data lapangan (in-situ) titik titik FG pada area yang sama (lokasi penelitian). Dilakukan perhitungan persentase akurasi dengan menggunakan analisa statistik. Dari model yang dibangun, akan dipahami bahwa kehandalan unjuk-kerja dari model prediksi yang dihasilkan akan bergantung pada umpan balik (feedback) dari data in-situ yang diperoleh dari survei lapangan.

\subsubsection{Rancangan Online System}

Dalam upaya memudahkan pengguna (user) untuk mengakses data kualitas lingkungan perairan dan data $F G$, maka dalam riset ini, model yang diusulkan, diimplementasikan dalam sistem online (spatial online system). Kontribusi dari hasil riset ini bagi iptek adalah pengembangan model untuk aplikasi dalam pengembangan Sistem Perikanan Tangkap Terpadu berbasis website spasial (online system). Diharapkan sistem ini dapat menyediakan informasi yang tepat guna mengenai lokasi FG yang mudah diakses, cepat dan akurat serta diharapkan bisa membantu meningkatkan pendapatan dan kesejahteraan 
masyarakat nelayan khususnya, perekonomian daerah dan devisa negara dari sektor industri perikanan tangkap.

\section{HASIL DAN PEMBAHASAN}

Dari proses eksperimen yang telah dilakukan diatas, diperoleh formulasi aturan-aturan heuristik (heuristic rules) yang digunakan untuk memprediksi lokasi penangkapan ikan (fishing ground) berdasarkan metode/model sistem cerdas. Sekumpulan Aturan-aturan (heuristic rules) dalam bentuk "IF-THEN Rule" yang diakuisisi dari pakar (expert) telah digunakan dalam membangun sistem pemantauan kualitas lingkungan perairan dan sistem prediksi lokasi FG ditunjukkan pada Tabel 1. Pada Tabel 1, dihasilkan 12 aturan (heuristic rules) yang diakuisisi dan diformulasi dari basis pengetahuan (knowledge based) yang dibuat oleh expert system. Aturan-aturan (rules) ini merupakan formulasi "IF-THEN Rule" yang diolah didalam sistem "inference engine" untuk menentukan secara tepat lokasi FG melalui pemetaan kondisi kualitas lingkungan perairan di lokasi riset. Dengan demikian, prediksi lokasi FGD dilakukan secara otomatis dan akurat.

Tabel 1. Heuristic rules yang diperoleh dari akuisisi pengetahuan yang dihasilkan oleh expert system digunakan dalam memantau kualitas lingkungan perairan dan prediksi lokasi penangkapan ikan (fishing ground)

\begin{tabular}{|c|c|c|c|c|c|}
\hline Attribute & Rule & Co & ditions & Conseg & \\
\hline 1 & 1 & IF & $\begin{array}{l}\text { SST (range : } 24^{\circ} \mathrm{C}-27^{\circ} \mathrm{C} \text { ) with different } 1.5^{\circ} \mathrm{C} \\
\text { Diameter }>10 \mathrm{~km} \\
\text { Located }>4 \text { mile sea line with area } 100 \mathrm{~km}^{2}\end{array}$ & $\begin{array}{l}\text { AND } \\
\text { AND } \\
\text { THEN }\end{array}$ & This location call FRONT \\
\hline 1 & 2 & IF & FRONT have V (speed Value) $=5 \mathrm{~cm} / \mathrm{s}$ & THEN & This location is Fishing Ground \\
\hline 1 & 3 & IF & $\begin{array}{l}\text { SST (range : } 24^{\circ} \mathrm{C}-27^{\circ} \mathrm{C} \text { ) with different } 2^{\circ} \mathrm{C} \\
\text { Diameter }>30 \mathrm{~km} \\
\text { Located }>4 \text { mile sea line with area } 100 \mathrm{~km}^{2} \\
\text { Depth }>100 \mathrm{~m} \\
\text { Length }>10 \mathrm{~km}\end{array}$ & $\begin{array}{l}\text { AND } \\
\text { AND } \\
\text { AND } \\
\text { AND } \\
\text { THEN }\end{array}$ & This location is EDDY CURRENT \\
\hline 1 & 4 & IF & $\begin{array}{l}\text { EDDY CURRENT have R }>100 \mathrm{~km} \\
\mathrm{~V} \text { (speed value) } 10 \mathrm{~cm} / \mathrm{s}\end{array}$ & $\begin{array}{l}\text { AND } \\
\text { THEN }\end{array}$ & This location is Fishing Ground \\
\hline 1 & 5 & IF & $\begin{array}{l}\text { SST range }<24^{\circ} \mathrm{C} \\
\text { SST range }>27^{\circ} \mathrm{C} \\
\end{array}$ & $\begin{array}{l}\text { AND } \\
\text { THEN }\end{array}$ & This location is non Fishing Ground \\
\hline 2 & 6 & IF & $\begin{array}{l}\text { Chl-a concentration range } 0.3-2.5 \mathrm{mg} / \mathrm{m}^{3} \\
\text { Area located }>4 \text { mile sea line } \\
\text { Depth more than } 100 \mathrm{~m} \\
\text { Area is } 100 \mathrm{~km}^{2}\end{array}$ & $\begin{array}{l}\text { AND } \\
\text { AND } \\
\text { AND } \\
\text { THEN }\end{array}$ & This location is UPWELLING AREA \\
\hline 2 & 7 & IF & UPWELLING AREA & THEN & This location is Fishing Ground \\
\hline 2 & 8 & IF & $\begin{array}{l}\text { Chl-a concentration }<0.3 \mathrm{mg} / \mathrm{m}^{3} \\
\text { Chl-a concentration }>2.5 \mathrm{mg} / \mathrm{m}^{3}\end{array}$ & $\begin{array}{l}\text { AND } \\
\text { THEN }\end{array}$ & This location is non Fishing Ground \\
\hline 3 & 9 & IF & $\begin{array}{l}\text { Turbidity value less than } 10 \mathrm{mg} / \mathrm{tt} \\
\text { Located }>4 \text { mile sea line } \\
\text { Depth }>100 \mathrm{~m} \\
\text { Area }>100 \mathrm{~km}^{2}\end{array}$ & $\begin{array}{l}\text { AND } \\
\text { AND } \\
\text { AND } \\
\text { THEN }\end{array}$ & This location is UPWELLING AREA \\
\hline 3 & 10 & IF & UPWELLING AREA & THEN & This location is Fishing Ground \\
\hline 3 & 11 & IF & $\begin{array}{l}\text { Turbidity have Chl-a concentration range } 0.3-2.5 \mathrm{mg} / \mathrm{m}^{3} \\
\text { Located }>4 \text { mile from sea line } \\
\text { Depth more than } 100 \mathrm{~m} \text {; Coverage Area }>100 \mathrm{~km}^{2}\end{array}$ & $\begin{array}{l}\text { AND } \\
\text { AND } \\
\text { AND } \\
\text { THEN }\end{array}$ & This location is UPWELLING AREA \\
\hline 3 & 12 & IF & UPWELLING AREA & THEN & This location is Fishing Ground \\
\hline
\end{tabular}

\subsection{Pemantauan Kualitas Lingkungan Perairan Banggai Kepulauan, Sulawesi Tengah}

Pada Gambar 5 ditunjukkan kualitas lingkungan perairan Banggai Kepulauan, berupa kondisi konsentrasi klorofil dan konsentrasi suhu permukaan laut (sea surface temperature/SST) bulanan (periode tahun 2007-2014) menggunakan data citra satelit MODIS. Dari hasil analisis, diperoleh kondisi konsentrasi klorofil dan SST dapat dimonitor, baik harian maupun bulanan dengan cepat dan akurat.

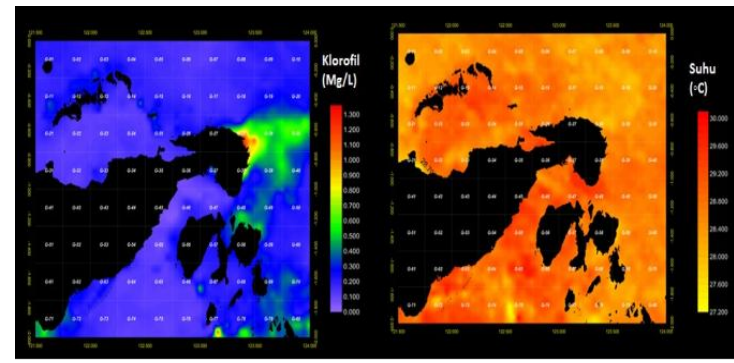

Ket: warna merah: konsentrasi chl-a tinggi; warna kuning: konsentrasi chl-a sedang; dan warna hijau: konsentrasi chl-a rendah

Gambar 5. Konsentrasi Klorofil dan Suhu Permukaan Laut Bulanan Periode Tahun 2017-2014 
Hasil pemantauan klorofil dan SST disini akan digunakan sebagai acuan dalam melakukan prediksi densitas FG menggunakan model prediksi yang telah dibangun (intelligent fish tracker). Konsentrasi klorofil yang terbesar terdapat di lingkungan perairan di ujung pulau (berwarna merah, kuning dan hijau).

Sedangkan konsentrasi rendah menyebar di sekitar pesisir pulau. Sedangkan, konsentrasi SST diperlihatkan menyebar secara merata disekitar lingkungan perairan.

\subsection{Sistem Prediksi Lokasi Penangkapan Ikan (Fishing Ground)}

Untuk memverifikasi dan validasi hasil yang diperoleh dari model prediksi yang telah dibangun (intelligent fish tracker), dilakukan perbandingan hasil pengukuran data dari survei lapangan (insitu) dengan data dari satelit penginderaan jauh. Pada Gambar 6, ditunjukkan grafik hasil perbandingan antara pengukuran berdaarkan insitu dengan pengukuran dengan satelit penginderaan jauh.

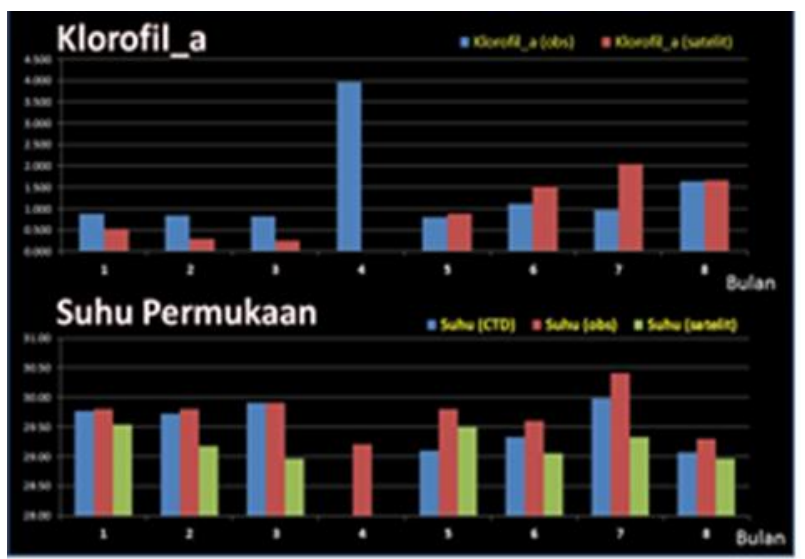

Gambar 6. Perbandingan Hasil Pengukuran in-situ dengan Satelit (validasi hasil)

Dari hasil perbandingan tersebut, diperoleh nilai tingkat akurasi diatas 93\% untuk lokasi perairan Banggai Kepulauan dan sekitarnya. Dapat disimpulkan, bahwa model prediksi "intelligent fish tracker" memiliki kemampuan dan unjuk kerja (performance) yang tinggi dalam memantau kondisi lingkungan perairan dan memprediksi lokasi penangkapan ikan (FG).

Pada Gambar 7, ditunjukkan peta sebaran lokasi penangkapan ikan (fishing ground) bulanan (Januari-Desember) periode tahun 2007-2014 di wilayah lingkungan perairan Pesisir Banggai Kepulauan, Provinsi Sulawesi Tengah. Peta sebaran densitas lokasi penangkapan ikan (FG) tersebut diperoleh dari model prediksi "Sistem Penjejak Ikan nan Cerdas/intelligent fish tracker", dimana sebagai masukan digunakan 3 parameter, yaitu: suhu permukaan laut (SST), Konsentrasi klorofil (chl) dan Turbiditi. Sistem prediksi ini akan melakukan proses dan analisa, sampai menghasilkan peta densitas lokasi penangkapan ikan (fishing ground map). Lebih lanjut, pada Gambar 6, ditunjukkan hasil sebaran densitas lokasi penangkapan ikan (FG) dari bulan Januari sampai bulan Desember. Dari hasil analisis, ditunjukkan pada bulan Juli dan bulan Agustus memiliki densitas sebaran lokasi FG yang tertinggi. Sehingga, dapat disimpulkan bahwa pada bulan tersebut kondisi lingkungan perairan di lokasi tersebut memiliki tingkat kesuburan yang dibandingkan dengan bulan lainnya.

Pada Gambar 8, dengan jelas diperlihatkan sebaran komposit densitas lokasi penangkapan ikan (FG) dari tahun 2007-2014. Densitas FG tertinggi ditunjukkan denga warna merah, sedang yang lebih rendah ditunjukkan dengan warna kuning.

Peta lokasi sebaran komposit densitas FG (FG map) beserta titik koordinatnya, selanjutnya diinformasikan kepada nelayan untuk digunakan sebagai panduan untuk menuju lokasi penangkapan ikan. Dengan panduan ini, nelayan dapat menangkap ikan lebih efektif dan efisien, karena tujuan sudah jelas dan yang lebih penting lagi nelayan dapat menghemat penggunaan bahan bakar kapalnya.

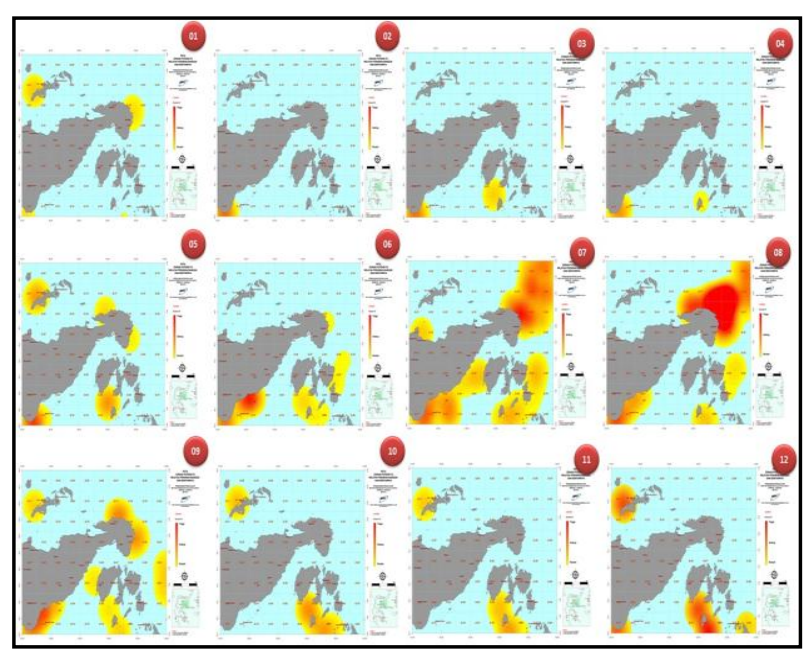

Gambar 7. Sebaran Fishing Ground Bulanan (Januari-Desember) Periode Tahun 2007-2014 


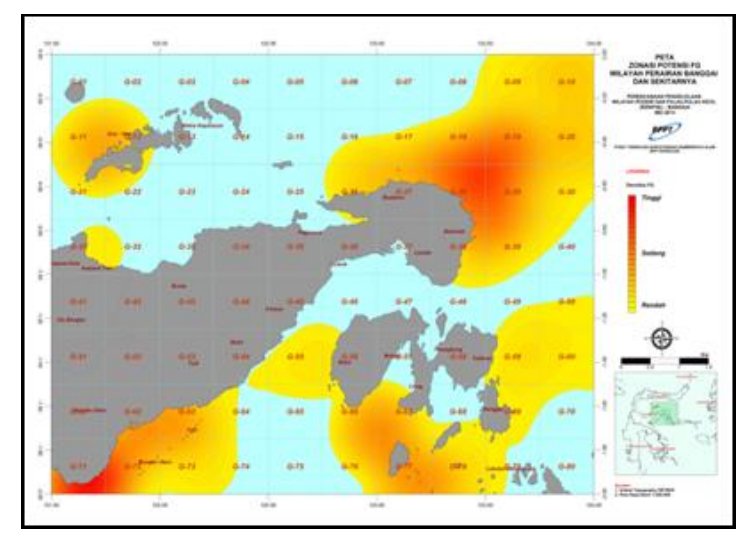

Gambar 8. Sebaran Densitas Komposit FishingGround dari Tahun 2007-2014

Ket: Warna merah: densitas tinggi; warna kuning: densitas lebih rendah)

Hasil yang ditunjukkan dari Gambar 8, dengan mengetahui sebaran densitas lokasi penangkapan ikan, maka sangat bermanfaat bagi para nelayan untuk melakukan penangkapan ikan dengan efektif dan efisien dan dengan sasaran tangkapn yang jelas berdasarkan panduan peta FG yang sudah dihasilkan tersebut. Lebih lanjut, nelayan dapat membuat perencanaan, seperti kapan dan dimana harus menangkap ikan, alat tangkap apa yang diperlukan serta jarak tempat pendaratan ikan (TPI) yang mana yang bisa mereka singgah untuk menjual hasil tangkapannya.

\subsection{Sistem Berbasis Spasial Online}

Konsep dasar rancangan imlementasi model prediksi yang dibangun berbasis Spatial Online System adalah agar informasi dan pengetahuan terkait sumberdaya kelautan dan perikanan dapat bermanfaat bagi pengguna, karena memungkinkan pengguna melakukan akses secara cepat, tepat dan akurat dimanapun berada untuk mendapatkan informasi FG dan informasi terkait lainnya.

Komponen online system terdiri dari: komponen komunikasi, browser, sindikasi, bahasa pemrograman, data tematik, format data, basis data, dan komponen lainnya, yang kesemuanya diharapkan mampu mendukung bekerjanya perangkat "Intelligent Fish Tracker" secara online. Sistem online ini dapat diakses melalui server BPPT melalui alamat: http://tisda.bppt.go.id/sikbes.

Pada Gambar 9, ditunjukkan visualisasi hasil dari implementasi sistem prediksi yang diusulkan kedalam sistem online. Pengguna dapat mengakses data, informasi dan pengetahuan secara cepat dan akurat. Misalnya, data kondisi kualitas lingkungan perairan (kesuburan perairan) serta data lokasi penangkapan ikan, dan data terkait lainnya, baik periode harian, 3 harian, 8 harian maupun bulanan. Dalam sistem online memungkinkan pengguna melakukan proses lebih lanjut dari data yang tersedia untuk kebutuhan aplikasi tertentu.

Dalam sistem online, ketersediaan dan kehandalan sistem internet sangat penting agar akses data bisa dilakukan secara cepat.

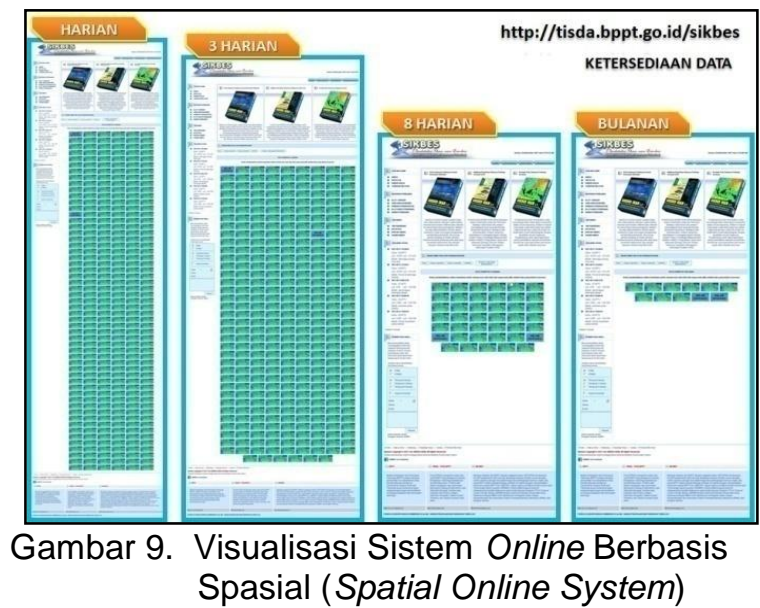

\section{KESIMPULAN}

Dalam riset ini telah diperkenalkan suatu pendekatan baru (new approach) yang digunakan untuk pemantauan kualitas lingkungan perairan dan prediksi lokasi penangkapan ikan di perairan Banggai Kepulauan, Provinsi Sulawesi Tengah. Knowledge-based expert system yang diintegrasikan dengan teknologi penginderaan jauh dan sistem informasi geografis (SIG) yang disebut dengan "sistem penjejak ikan nan cerdas (intellgent fish tracker)".

Kehandalan model yang diusulkan ini telah di demonstrasikan dalam melakukan pemantauan kualitas lingkungan perairan dan prediksi lokasi penangkapan ikan (FG) dengan hasil yang cepat, tepat dan memiliki tingkat akurasi yang lebih tinggi dibanding metode konvensional yang selama ini digunakan. Untuk menguji kehandalan unjuk kerja (performance), model prediksi yang dibangun di verifikasi dan divalidasi dengan data survei lapangan (in-situ data) di lokasi dan waktu yang sama.

Dari hasil yang diperoleh menunjukkan densitas sebaran fishing ground dan pemantauan kualitas lingkungan perairan di perairan Banggai Kepulauan yang dihasilkan dari model yang diusulkan ini menghasilkan tingkat akurasi lebih dari 93\%. Agar sistem ini bermanfaat bagi pengguna, model sistem prediksi ini telah diimplementasikan berbasis online. Dengan sistem online, pengguna dapat melakukan akses secara cepat dan tepat dimana saja. Aplikasi sistem ini dapat memberikan manfaat besar bagi para nelayan, khususnya dalam meningkatkan efisiensi dan produksi dari suatu proses produksi penangkapan ikan di suatu wilayah perairan; 
memberikan manfaat secara luas dalam proses pengelolaan sumberdaya perikanan di perairan nusantara, sehingga pada akhirnya dapat dijadikan sebagai landasan kebijakan dalam menyusun program pengelolaan sumberdaya perikanan laut secara berkelanjutan (sustainable fishery management) skala nasional.

\section{PERSANTUNAN}

Penulis mengucapkan terima kasih yang tinggi kepada BPPT, khususnya Direktur Pusat Teknologi Inventarisasi SDA, Kedeputian TPSA yang telah memotivasi, memberi dorongan untuk menyelesaikan riset ini sampai memasuki fase operasional (implementasi). Terima kasih kepada Dr. Ir. Subandono D. (Pusat Panataan Ruang Kementerian Kelautan dan Perikanan RI) yang telah menerapkan produk inovasi ini untuk kegiatan Zonasi Penentuan Wilayah Perikanan Tangkap KKP. Terima kasih juga ditujukan kepada semua anggota Tim Pengembang Sistem yang telah bekerja keras menghasilkan inovasi teknologi yang sudah bisa diterapkan di berbagai lokasi di wilayah NKRI.

\section{DAFTAR PUSTAKA}

1. Atkinson, P.M., And A. R. L. Tatnall, (1997), Neural networks in remote sensing, Int. J. Remote Sensing, 18 (4):1-10.

2. Degnbol, P., (2004), The Knowledge base for fisheries management in developing countries: alternative approaches and methods, Institute for Fisheries Management and Coastal Community Bergen Norway Published.

3. Hendee, J.C., (1998), An Expert System for Marine Environmental Monitoring in the Florida Keys national Marine Sanctuary and Florida Bay, Proceedings of the Second International Conference on Environmental Coastal Regions, ed. C.A. Brebbia, Computational Mechanics Publications/ WIT Press. Southampton, (1): 57-66.

4. Laurs, R.M.,(1984), Albacore tuna catch distributions relative to environmental features observed from satellites, Deep-Sea Res., 31(9):1085-99.
5. Jensen, J.,(1996), Introductory Digital Image Processing. ERDAS IMAGINE User's Guide, Prentice Hall, New Jersey.

6. Holland, C.R., (1986), Artificial intelligence and the extraction of marine environmental information. Proceedings Marine Data Systems: Marine Data Systems, International Symposium, (1): 433-436.

7. Ignizio, J.P, (1998), Introduction to Expert Systems:the development and implementation of rule-based expert system". NewYork: McGraw-Hill, Inc.

8. Ryan, J.D., And P.E., Smith, (1985), An expert system for fisheries management. Oceans Proceedings: Ocean Engineering and The Environment,(2): 1114-1117.

9. Sigilito, V., R. Wachter, And R. Jr.,Xcor., Hunt (2009), A knowledge-based system for correction of oceanographic reports, IEEE Symposium: Expert Systems

10. Mockler, R.J. \& D.G. Dologite, (2010), Knowledge-Based Systems. An Introduction to Expert Systems. Macmillan Publishing, New York

11. M. Sadly, Awaluddin, Y. Faizal, (2009), Assessment and Applications of the Knowledge-based Expert System in Natural Resources Management, Technical Report P-TISDA, BPPT.

12. Venegas, R., P.T. Strub, E. Beier, Letelier, T. Cowles, and A.C. Thomas, (2007), Assessing satellite-derived variability in chlorophyll pigments, wind stress, sea surface height, and temperature in the northern California Current System, J. Geophys. Res..

13. Hendiarti, N., H. Siegel, T. Ohde, (2004), Investigation of different coastal processes in Indonesian waters using SeaWiFS data. Deep Sea Research Part II 51 : 85-97.

14. Kemmerer, A.J., (1980), Environmental preferences and behavior patterns of Gulf menhaden (Brevoortia patronus) inferred from fishing and remotely sensed data, ICLARM Conf.Proc., (5):345-70.

15. Barrett, E.C. and L.F. Curtis, (2012), Introduction to Environmental Remote Sensing, Chapman \& Hall. 